\title{
Professional Learning Through Everyday Work: How Finance Professionals Self-Regulate Their Learning
}

\author{
Allison Littlejohn ${ }^{1,2}$ (D) Colin Milligan ${ }^{1}$. \\ Rosa Pia Fontana ${ }^{1}$ - Anoush Margaryan ${ }^{1}$
}

Received: 6 January 2015 / Accepted: 2 December 2015 /

Published online: 7 January 2016

(C) The Author(s) 2016. This article is published with open access at Springerlink.com

\begin{abstract}
Professional learning is a critical component of ongoing improvement and innovation and the adoption of new practices in the workplace. Professional learning is often achieved through learning embedded in everyday work tasks. However, little is known about how professionals self-regulate their learning through regular work activities. This paper explores how professionals in the finance sector (n-30) selfregulate their learning through day-to-day work. Analysis focuses on three subprocesses of self-regulated learning that have been identified as significant predictors of good self-regulated learning at work. A key characteristic of good self-regulation is viewing learning as a form of long-term, personalised self-improvement. This studyprovides a foundation for future policy and planning in organisations aiming to encourage self-regulated learning.
\end{abstract}

Keywords Self-regulated learning · Professional learning · Workplace learning · Finance sector

\section{Professional Learning and Work}

Professional learning is a critical component of ongoing improvement and innovation and the adoption of new practices. In today's knowledge intensive workplaces, intentional learning experiences, such as training or educational processes, are no longer an effective way to learn, as each professional's working practice evolves and learning needs change continually (Littlejohn and Margaryan 2013). There is evidence that professional learning is achieved primarily on-the-job and is deeply intertwined with,

Allison Littlejohn

allison.littlejohn@open.ac.uk

1 Caledonian Academy, Glasgow Caledonian University, Glasgow, UK

2 Present address: Institute of Educational Technology, The Open University, Milton Keynes, UK 
and mediated through, everyday work tasks (Collin 2004; Eraut 2004; Tynjälä 2008) and interactions with other people (Eraut 2007; Collin 2008). This means that the responsibility for learning shifts from the training department to professionals, who must manage their own learning for work. These changes place increasing demands on professionals to self-regulate their learning effectively (Sitzmann and Ely 2011). Individuals must continually plan, perform and monitor their learning needs, balancing structured training with work-based learning (Billett et al. 2008; Eraut 2004). However, little is known about how professionals self-regulate their learning through everyday work. Aiming to reduce this gap in knowledge, this study examines how professionals self-regulate their learning. The paper begins with a review of professional learning and self-regulated learning at work. Specific processes of self-regulation significant for workplace learning are described in detail in a 'Foundations' section. The method and context are outlined, and then results are presented and discussed. The paper concludes with a summary of the main findings and implications, alongside a reflection on the limitations of the study and prospects for future research.

\section{Professional Learning Through Everyday Work}

Learning can be difficult to measure or identify in everyday work settings. It can be argued that a change in work practice is a sign that professionals have learned. Change in practice requires the construction of conceptual and practical knowledge, as well as the development of socio-cultural and self-regulative knowledge (Eraut 2004; Tynjälä 2008; Littlejohn and Hood forthcoming). Concurrent construction of multiple types of knowledge is most readily achieved through the integration of training with on-the-job learning (Tynjälä 2008; Eraut 2000). In this way, work and learning are intertwined (Stenström and Tynjälä 2009) and learning is determined by, and integrated with, work tasks and priorities (Billett 2004). Here, the workplace operates as a site where learning is both undertaken and applied and learning is shaped by the individual's connection to and interaction with this environment (Harteis and Billett 2008; Billett 2004). From this perspective, professional learning can be viewed as a reciprocal process shaped by the affordances of a specific workplace environment resources, materials and people - along with the individual's ability and motivation to engage with what is afforded (Billett 2004; Fuller and Unwin 2004; Littlejohn and Hood forthcoming). Knowledge is distributed across the numerous resources, materials and people that make up the workplace. Therefore, 'knowing' comes into being through various forms of participation, formed through negotiations between multiple individuals within collective units - groups, teams and collectives (Engeström 2014). These forms of interaction both support and mediate self-efficacy (Bandura 1982). Learning is most readily recognised when it is achieved through planned training or mentoring, yet professional learning is often experiential and work-based, rather than planned (Eraut 2004). By contrast, learning through everyday work is nuanced; sometimes it is intentional and acknowledged; for example, when asking a colleague for help. Other times learning is unacknowledged; for example, working within a new context and culture and changing practice over time. Eraut (2000) uses the term 'informal learning' to describe learning that takes place in the spaces surrounding training activities and events, propelled by individual agency, providing a contrast to education processes (Eraut 2000). Professionals are more enabled to engage in learning when they work autonomously to create new knowledge (Marsick and Watkins 
1990; Enos et al. 2003). The knowledge they create may be explicit and easily recognised or tacit and so embedded that it can be difficult to explicate (Eraut 2000). This perspective makes it difficult to discern the division between 'learning' and 'work' and it may be challenging for professionals to recognise instances of learning (Argyris and Schön 1992; Engeström 1999).

\section{Agency and Self-Regulated Learning}

Learning is dependent on the cognitive engagement and agency of each individual. Each professional's ability and motivation to engage in learning is mediated through interagency, as professionals engage with and learn from work tasks, new opportunities and other people (Collin 2008; Tynjälä 2008; Unwin et al. 2004; Stacey 2001, p. 62). The individual's personal agency in learning is influenced by a combination of psychological (cognitive and affective), behavioural and environmental factors that form the foundation of self-regulated learning (Zimmerman 1989, 2000; Pintrich 2000; Bandura 1986). Some factors, for example, goal-setting and learning approaches, are characteristics of the learner that can be improved through practice. Other characteristics, such as interest, motivation and self-satisfaction, may be influenced by affective components (Winne 1995; Zimmerman 2000). This observation has at least two important consequences for professional learners. First, the factors that influence each individual's ability to self-regulate their learning are likely to be significant in professional learning situations, where individuals rely on internal drive and personal agency to learn (Enos et al. 2003). Second, self-regulation blends different forms of deliberative or non-deliberative cognitive engagement (Winne 1995). which is characteristic of workplace learning. There is evidence that professionals alter their self-regulation and adapt their learning to attain work goals (Sitzmann and Ely 2011). Although there are studies of how workers' learning is mediated by their own agency and intentionality, little is known specifically about self-regulated learning in professional contexts.

van Eekelen et al. (2005) carried out a qualitative study in the Netherlands exploring how college teachers self-regulate their learning within teaching practice. Interviews and diaries were used to gather data from 15 teachers on 86 'learning episodes'. The study found evidence of teachers changing their practice, which was assumed to be a sign of learning. Much of the learning observed was reactive and recognised only after the event, such as a remark from a colleague that helped improve practice. Another qualitative study, by Margaryan et al. (2013). examined professional learning in a multinational energy company. There was evidence of professionals purposefully self-regulating and aligning learning with outcomeoriented goals focused on specific work tasks. However, self-regulation was socially mediated by the consequences of self-regulation activities; experts were more inclined to share their expertise where they recognised benefits (Margaryan et al. 2009). Willingness to share knowledge and expertise is an important factor to support selfregulation and learning across sites (Eraut 2007; Edwards 2010, p.10; see also Ludvigsen et al. 2010 for a review of issues of significance). Schulz and Stamov Roßnagel (2010) carried out a quantitative analysis of workplace learning in a mail order company in Germany. They found that each individual's ability to self-regulate their learning was a predictor of (self-identified) learning success. This ability was 
described by the authors as 'learning competence', drawing on previous work exploring student learning by van den Boom et al. (2004). Specific self-regulation strategies that are important for learning include the ability to set learning goals, to plan, monitor and evaluate learning and a 'positive learning orientation'. Harbouring an interest in expanding knowledge, skills and abilities (learning approach orientation), combined with a readiness to invest substantial learning efforts (negative association between work-avoidance orientation and learning success) are important constituents of learning competence. These studies provide a general overview of self-regulated learning in the workplace. However, there is a gap in the literature limiting our understanding of how professionals self-regulate their learning. This study aims to contribute to closing the gap in this knowledge.

\section{Foundations of this Study}

This analysis is one component of a larger study exploring self-regulated learning strategies of professionals. The study focuses on knowledge workers in the financial services industry, an area of work which has been impacted by significant government-enforced regulation in many Western countries following the global economic crisis of 2008. Changes within the sector have necessitated agile transformation in professional practice to develop new industry processes. In these circumstances professionals often work at the boundary of their knowledge and personal expertise. The study participants were Associates and Members of the Chartered Institute for Securities \& Investment (CISI), an international professional body. The first phase of the study was a quantitative analysis of the relationship between self-regulated learning and workplace learning activity, pinpointing SRL factors that predict learner agency. The findings from this initial quantitative analysis provide a foundation for the second, qualitative phase presented in this paper.

Phase 1 data were gathered using the validated SRL Workplace Questionnaire (SRLWQ: available from: http://dx.doi.org/10.6084/m9.figshare.1146236) (Fontana et al. 2015). The instrument measures nine factors corresponding to nine sub-processes of SRL, previously identified by Zimmerman (2000) and Pintrich (2000). Goal setting, Strategic planning, Self-efficacy, Task interest and value, Task strategy, Elaboration, Critical thinking, Self-evaluation, and Self-satisfaction. Linear regression analysis probed the relationship between self-regulated learning and workplace learning activity ( $n=170$ : Milligan et al. 2015). There was a positive relationship between self-regulated learning and workplace learning activity, with higher SRL (as perceived by the learners and measured by the SRLWQ) predicting greater uptake of professional learning opportunities outside education and training. Using the self-perception scores of each of the nine SRL sub-processes from the 170 respondents, a linear regression analysis pinpointed three sub-processes that have a significant positive effect on this relationship: Task interest and value, Task strategies, and Self-evaluation:

- Task interest and value is the intrinsic value of learning perceived by the learner. In education, self-regulated learners consider the intrinsic value of each learning task, viewing successful completion of tasks as a step towards longer-term goals (Zimmerman 2000). This long-term view means that self-regulated learners look beyond the immediate, short-term learning outcome and pay attention to the long- 
term process of learning, which, in turn, sustains the individual's motivation to learn. Whether and how interest in learning influences professional learning is relatively unknown.

- Task strategies are the approaches and methods each learner applies in order to learn. In education, self-regulated learners tend to utilise a wide range of task strategies to support their learning (Zimmerman 2000; Zimmerman and Martinez Pons 1986). However, little is known about the strategies used by professionals.

- Self-evaluation is the learner's comparison of self-observed performance against some external standard, such as another person's performance (Zimmerman 2002). For self-evaluation and self-judgment to be effective, learners must take into consideration the context and expected outcomes and accurately compare themselves with external benchmarks (Zimmerman 2002). In education and training, these benchmarks are understood: the learner's prior achievements, another person's performance or an absolute standard of performance (assessment). Benchmarks in the workplace could be performance targets, goals set by clients or customers, or performance levels of other people or organisations. Little is known about how professional learners self-evaluate their own learning. Learners who aim to reach a high level of expertise set challenging criteria for themselves (Ericsson and Lehmann 1996).

While the linear regression analysis identified the three most significant subprocesses that mediate professional's learning, quantitative data provides little insight into how these three sub-processes are operationalised by the finance professionals. To understand these sub-processes and their significance, phase 2 of the study was designed to combine the quantitative data provided by the SRLWQ instrument with qualitative data on why and how professionals self-regulate their learning. The method is described in the next section.

\section{Method}

A qualitative method was designed to explore how finance professionals self-regulate their learning through task interest and value, task strategies, and self-evaluation. Three qualitative methods were considered: semi-structured interviews, learning diaries and ethnographic observation. Ethnographic approaches, such as shadowing and observation, provide a useful approach in developing a rich understanding of professionals' learning practice in the workplace (Collin 2008). Eraut (2000) observed that, while onthe-job learning can at times be intentional and deliberate, at other times it can be spontaneous and reactive. Ethnographic observation may provide valuable insights into socio-cultural aspects of learning in settings where professionals may (or may not) purposefully self-regulate their learning (Eraut 2004). However, there are two reasons why ethnographic studies were not selected. First, the professionals in this study were located in eighteen different organisations; it was therefore not feasible to place researchers on site. Second, while both socio-regulative (mainly cultural) and selfregulative (largely cognitive and affective) features of learning are significant, this study emphasises individual, self-regulative learning which ethnographic data cannot provide. Diary studies or logbooks were also considered as a means of capturing descriptions of 
individual learning in near real-time. However, the diary approach does not allow the researcher to question and probe areas of interest. Probing and facilitation is particularly important in this type of study. Professional learning is often embedded within work and not recognised as learning, so it is difficult for professionals to identify when they have learned (Eraut 2004). Acknowledgement of on-the-job learning may require appropriate facilitation (Eraut 2004, p. 249). One method that allows facilitation is interview.

The popularity of interviews is most likely because these are the easiest to arrange (Eraut 2004, p.248). However, during interviews professionals report on their learning 'after action' and may not have a clear recollection of what and how they learned 'in action' (Eraut 1995). As a form of self-report, interview data may also represent what the respondent perceives the researcher wants to hear, rather than what they believe (Rausch 2013). Nevertheless, since it may be difficult for professionals to acknowledge learning embedded within their work practice, facilitated interviews may help the respondent to recall learning. Asking questions about 'learning' per se is not likely to be helpful, because the respondent might have a tendency to focus on education and training, rather than on learning. The researcher has to be able to facilitate the interview appropriately in order to support the interviewee in identifying and describing learning. This involves questioning that may include asking the interviewee to identify a recent task where they had to change practice, then probing instances of implicit learning, slow gradual learning or tacit knowledge (Eraut 1995). The interviewer has to tease out specific points of interest, without influencing the responses. Probing specific areas is important because, as Eraut (2000) observes, employees usually wish to present themselves as 'professional', which means they tend to report positive results and evade the negative outcomes of work. Weighing up these factors, a combination of logs, followed by carefully facilitated, semi-structured interviews, were selected as the most appropriate method. There were two main reasons: the logs provided an example of learning as a starting point for the interviews. Facilitated interviews allowed the researcher to expedite recall of learning through work. However, it is acknowledged that self-report methods are imperfect.

On completion of the SRLWQ, study participants $(n=170$, members of the Chartered Institute of Securities \& Investment) were invited to volunteer to participate in a semi-structured interview. Those who agreed to participate $(n=30)$ were emailed in advance and prompted to identify and $\log$ a recent project or assignment that had changed their practice and triggered learning. The log provided one or more scenarios of learning through work tasks (rather than education or training). These scenarios provided a focal point for semi-structured, facilitated interviews (script available at http://dx.doi.org/10.6084/m9.figshare.1146247) designed to probe the same nine SRL sub-processes measured by the SRLWQ instrument. Interviews were conducted and recorded during June and July 2013. The 30 interviewees (21 male and 9 female) represented a range of diverse roles (14 senior managers, 9 frontline managers, 7 frontline staff) across 18 organisations primarily in the United Kingdom. Their average age was $50.87(S D=6.97)$ and they had worked in their current organisation for an average of $19.2(S D=14.28)$ years.

The interview transcripts were coded and analysed in three successive rounds. First, the 30 interview transcripts were coded independently by two researchers. The codes assigned corresponded to the self-regulated learning sub-processes identified by the quantitative analysis. Second, each participant was assigned a rank (1-30) 
corresponding to their score for each individual SRL sub-process of interest, as well as a rank for their overall SRL score (see Table 1 for a summary). Participants who scored highest and lowest for each of the sub-processes, representing the top and bottom quartile, were selected (the number selected varied between 7 and 10, as sometimes there were several participants with the same rank). Third, coded transcripts were used to identify emergent themes in each sub-group. The transcripts were examined by two researchers, first independently to reduce the risk of bias, and then jointly to resolve differences. The groups of professionals who perceived their self-regulation as good or low did not differ significantly in terms of age, gender or number of years spent in the organisation (Mann-Whitney tests: Age: $\mathrm{U}(28)=164.5, \mathrm{Z}=-.91, \mathrm{p}=$ n.s.; gender: $\mathrm{U}(28)=99, \mathrm{Z}=-.48, \mathrm{p}=$ n.s.; organisation: $\mathrm{U}(28)=91.5, \mathrm{Z}=-.75, \mathrm{p}=$ n.s.).

Table 1 Participant profile summary

\begin{tabular}{|c|c|c|c|c|c|c|}
\hline $\begin{array}{l}\text { Participant } \\
\text { ID }\end{array}$ & Gender & Role & $\begin{array}{l}\text { SRL } \\
\text { rank }\end{array}$ & $\begin{array}{l}\text { Task interest } \\
\text { and value rank }\end{array}$ & $\begin{array}{l}\text { Task strategies } \\
\text { rank }\end{array}$ & $\begin{array}{l}\text { Self-evaluation } \\
\text { rank }\end{array}$ \\
\hline 62 & M & Director & 1 & 1 & 5 & 1 \\
\hline 68 & $\mathrm{M}$ & Manager, Internal Audit & 2 & 1 & 3 & 10 \\
\hline 80 & M & Financial Consultant & 3 & 21 & 1 & 13 \\
\hline 69 & M & Risk Manager & 3 & 11 & 8 & 5 \\
\hline 84 & $\mathrm{~F}$ & Manager & 3 & 11 & 8 & 5 \\
\hline 87 & $\mathrm{~F}$ & Manager, Operational Change & 6 & 1 & 12 & 13 \\
\hline 78 & $\mathrm{~F}$ & Senior Competition Manager & 7 & 11 & 15 & 5 \\
\hline 79 & M & Manager, Compliance & 8 & 11 & 5 & 30 \\
\hline 82 & M & Manager, Call Centre & 9 & 11 & 3 & 2 \\
\hline 88 & M & Credit Risk Manager & 10 & 1 & 15 & 2 \\
\hline 71 & $\mathrm{~F}$ & HR Professional & 11 & 20 & 10 & 13 \\
\hline 67 & $\mathrm{~F}$ & Manager, complaints & 12 & 11 & 10 & 18 \\
\hline 86 & M & Manager, Call Centre & 12 & 1 & 12 & 2 \\
\hline 75 & $\mathrm{~F}$ & Risk Manager & 14 & 11 & 12 & 10 \\
\hline 73 & M & Manager, compliance & 15 & 1 & 2 & 24 \\
\hline 64 & M & Risk Manager & 16 & 11 & 7 & 17 \\
\hline 61 & M & Director & 17 & 24 & 15 & 18 \\
\hline 66 & M & Analyst & 18 & 1 & 20 & 5 \\
\hline 81 & M & Compliance Officer & 19 & 21 & 15 & 5 \\
\hline 89 & M & HR Professional & 20 & 30 & 15 & 10 \\
\hline 70 & M & Finance Manager & 20 & 1 & 20 & 18 \\
\hline 72 & M & Manager, Customer Relations & 22 & 28 & 26 & 18 \\
\hline 77 & M & CEO, small business & 23 & 1 & 22 & 24 \\
\hline 65 & M & Associate Director & 24 & 1 & 28 & 13 \\
\hline 63 & M & Risk Analyst & 25 & 11 & 22 & 27 \\
\hline 85 & $\mathrm{M}$ & Manager, Finance & 26 & 21 & 29 & 24 \\
\hline 74 & $\mathrm{~F}$ & Manager & 27 & 24 & 22 & 27 \\
\hline 90 & $\mathrm{~F}$ & Risk Manager & 28 & 26 & 22 & 22 \\
\hline 83 & $\mathrm{~F}$ & Business Support Manager & 29 & 28 & 27 & 22 \\
\hline 76 & M & Business Support Manager & 30 & 26 & 30 & 27 \\
\hline
\end{tabular}


Coded interview data, reflecting in-depth instances of learning reported by finance professionals in facilitated interview settings, were analysed to identify each individual's task interest and value, task strategies while learning and self-evaluation. The results are presented and discussed in the following section.

\section{Results and Discussion}

This section reports the qualitative analysis of the data reflecting in-depth instances of professional learning reported by finance professionals. Results are reported on the most significant elements of self-regulated learning, as identified through an earlier linear regression analysis (Milligan et al. 2015). These results reflect each individual's task interest and value in learning (the first significant SRL sub-process), the task strategies and approaches they used while learning on-the-job (the second significant SRL sub-process), and how they self-evaluated their learning (the third significant SRL sub-process).

\section{Task Interest and Value}

Eight of ten professionals who reported good self-regulation perceived learning as having long-term value for their work and career. This outcome validates Zimmerman's (2000) concept of good self-regulation through task interest and value. For example, the Chief Executive of a small financial consultancy company who self-reported as a good self-regulated learner (62: ranked first equal for task interest and value and first for SRL) identified agile regulatory changes in the Finance Sector as an important element that raised his interest in learning. He described continuous learning as critical for self-enhancement to ensure his knowledge was current:

It's my business, the profile of my business is research, therefore this is what I have to do and I have to demonstrate that my company is able to have some understanding and some value.

Self-enhancement is a type of motivation that helps people to feel good about themselves and maintains self-esteem. Another example of interest and motivation to engage in self-enhancing behavior is a Credit Risk Manager who reported good selfregulation (88: ranked first equal for task interest and value, and tenth for SRL). In this case, interest was triggered through the experience of moving to a new work setting with a fresh style of management and working culture. The Manager learned how to operate within an open management culture with new forms of work relationships. He did not intentionally learn, yet over time, and through reflection, he realised that he had learned new knowledge and expertise useful for his future career. This form of learning has been described by Eraut (2004) as characteristic of learning through work performance. The Manager described the importance of identifying a component of work where he needs to focus attention and learn:

I think there needs to be a hook for me, to motivate my learning. But, once that hook is there, I'll throw myself into it. 
When attention has been focused and interest captivated, self-enhancement behaviour follows: 'I will launch into it once I'm enthused and motivated and engaged'. In this example, the work activity provides a focus for learning, such that learning is determined by and integrated with work, in agreement with the observations of Billett (2004) and Tynjälä (see Tynjälä 2008; Stenström and Tynjälä 2009). However, self-enhancing behaviour can also benefit performance in other areas of life outside work. A third participant, an Internal Audit Manager (68, ranked first equal for task interest and value, and second for SRL) also described how his interest in learning was heightened by the realisation that knowledge could be transferred to other contexts of application. The learning scenario he outlined also involved learning on-the-job. In this example, the Manager accepted a lead role in implementing a new risk management system for his organisation. The implementation process was bespoke and rigid, following a pre-set framework of steps. Although the process was unlikely to be repeated, the Manager recognised that the expertise he had learned in developing and implementing the process could be applied to future work settings or in his everyday life:

...that's what this learning process has taught me. So it's not only useful for your work, but it's also useful in your everyday life, to be able to go about it in a structured way and it's something that will last forever.

The experience was self-enhancing and he recognised the learning could be applied more widely than his immediate job.

By contrast, those who reported low SRL tended to focus on the immediate benefits of learning, with only two of seven articulating long-term self-improvement. All seven professionals who reported low SRL described learning in terms of their immediate work and described paybacks with regard to their team or organisation, rather than in terms of self-enhancement. For example, a Human Resource Manager working in employer relations (89: ranked 30th for task interest and value, and 20th for SRL) described learning as a 'solution' that had 'impact on the organisation' rather than as a process with personal, long-term benefits. When asked subsequently by the interviewer whether his interest was in learning or in fulfilling his role, he responded:

I think it's a balance of both. I think the aim was to solve the situation, but in doing so you also acquire new knowledge that you didn't have before.

His response signals recognition of the self-benefits of learning only after this explicit prompt, while his conscious focus was on solving the immediate problem. A Manager in a business support function who reported low SRL (participant 83, ranked 27th for task interest and value, and 29th for SRL) also provided evidence of focusing on acquiring the knowledge needed to complete a job task, rather than considering selfenhancement. The Manager needed to perform a risk assessment, drawing on policies and procedures which were new and unfamiliar. His focus was entirely on the task:

Obviously the outcome is to be able to execute the test and complete it ... within the required time scales because this task is time-bound. 
This example illustrates the influence of context on self-regulation. In this case, the Manager prioritised learning for immediate tasks over long-term self-enhancement, but he did not recognise that the work task may be solved and self-enhancement achieved at the same time, through a single process. The interview method makes it difficult to identify knowledge that may have been learned but not acknowledged (Eraut 2000) and the Manager may have acquired knowledge that is difficult to explain in detail.

A similar example is illustrated in the case of a Risk Manager with responsibility for resourcing and people capability (90: ranked 26th for task interest and value, 28th for SRL). When describing her learning she also focused on agile problem-solving, rather than considering self-enhancement and the long-term value of learning. She described the purpose of her learning as: 'that I could, in essence, deliver what was expected of me.' The learning scenario she described was being given responsibility for new tasks within a role she had held for several years. Deeper probing into the scenario identified affective factors associated with the context that may have prejudiced her interest and value in her learning, influencing her self-regulation:

It was a new task to me ... previously we had a team of four people who used to do that type of thing, but those roles were made redundant within our function due to some cost savings.

The terms 'made redundant' and 'cost savings' imply negative emotions that are in contrast to the positive feelings of self-esteem that characterise self-enhancement.

Overall, low self-regulators seem to focus on immediate improvement. Good selfregulators recognise that learning can simultaneously serve multiple purposes, such as immediate problem-solving as well as self-enhancement, and also understand that new knowledge may have application in unknown, future contexts.

\section{Task Strategies}

Professionals in this study were experienced, with the average length of service with their current employer being almost twenty years. Thus, we may expect they had already developed a range of strategies for learning (task strategies). Almost all the professionals we engaged with described situations of learning on-the-job where they used a range of task strategies and learning approaches; searching for information, note taking (text or illustration), gap analysis, help-seeking and eliciting feedback, problem solving, planning, and rehearsal. The choice of task strategy was often influenced by the nature of the learning scenario described and the resources available. These examples underscore the view of professional learning as reciprocally influenced by the affordances of the workplace and each individual's motivation to engage (Billett 2004; Fuller and Unwin 2004; Unwin et al. 2004).

From the earlier, quantitative study of self-regulated professional learning (Milligan et al. 2015) we know that workplace learning is influenced by the work task and the environment. The environment constrains the type of task strategies that can be used: a worker in a constrained context may have fewer opportunities to travel and work in different cultures than an international consultant. However, the data evidence is that, even in constrained environments, professionals can find ways to self-regulate. For 
example, an Investment Complaints Manager described how he learned to operate in a new role in a call centre (82: ranked third for task strategies, ninth for SRL).

I was looking at the job, understanding what the remit of the job was... and looking across that broad spectrum and deciding how best I could accomplish that in a very short period of time....

Taking a self-regulating approach, he asked his manager if he could 'shadow' an experienced colleague located at a different site. This example emphasises a number of important factors. First, the manager was actively regulating his learning, even though he worked in a relatively constrained environment. Second, he recognised the value of learning through negotiations with others and the significance of the social environment (Engeström 2014). However, individuals have to take an agentic stance to capitalise on the opportunities afforded by the work environment. The environment alone will not determine positive professional learning - the agency and self-regulation of the individual is important, particularly in recognising the necessity of varying task strategies to learn different types of knowledge. The Chief Executive of a financial consultancy company, introduced in the previous section (62: ranked fifth for task strategies, first for SRL), describes appreciation of concurrent construction of multiple types of knowledge in ways gauged important by Eraut (2000) and Tynjälä (2008):

You can't learn it all from a book. There's an awful lot that happens that's just not written down. And the financial market is like life, that not everything works in a logical parallel way, there's all sorts of things that happen which you have to deal with.

Analysis of the interview data revealed other differences between professionals who reported good self-regulation and those who did not, irrespective of their environment. These differences are illustrated in a case example of a Financial Consultant (participant 80: ranked first for task strategies, and third for SRL) who had to operate in a new country and culture. This Consultant had to learn the cultural norms of the financial market in a country with a culture he was unfamiliar with. His learning approaches were shaped by the nature of his job and included discussions with colleagues based in his local office who had first-hand experience of the culture he wanted to learn about, reading about contemporary history and demographics of the country of interest and travelling to the country. The range of task strategies he described were suited to learning diverse types of knowledge; factual knowledge was acquired through reading, while socio-cultural knowledge was learned through travel and interactions with colleagues in the country of interest. His discovery of how to learn was shaped by other colleagues' experience:

Because we've done it before and we know that the best way to find out things is by getting people's war stories, the people who have been there before.

Task strategies often involved interaction with colleagues, who sometimes acted as a 'sounding board', helping to develop new ideas. For example, a Compliance Manager 
(73: ranked second for task strategies and fifteenth for SRL) described how his manager had given him a challenging task to draft a particularly complicated and sensitive letter:

So, for example, when I was doing the letter, I managed to get various bits and pieces, so historical notes, various other things, dumped them all on to a bit of paper. It was easier to put lots and lots and lots of information and then type bits and pieces and then one weekend I went home and I started shaping the letter out of all the bits.

He looked for help from various people including his manager and people in his team, and from those beyond this core group. He selected specific people because of their expertise and ability to help him learn specific types of knowledge:

So there was a legal colleague... also the project manager was incredibly useful because if I needed something I would go to her and she would give it to me very quickly. The third person was probably... a colleague within another area of the bank who's been in this area for a long, long time. I've built a very good relationship with him and we work quite well together even though we're in different areas.

The third colleague mentioned in this case example was described as a 'sounding board'. Recognising the value of other people as a source of knowledge and developing the relational expertise required to pinpoint who to learn from is critical for professional learning (Edwards 2010). The Chief Executive described in the previous section (62, ranked fifth for task strategies, first for SRL) illustrates his understanding of the significance of help-seeking as a learning task strategy:

It's quite important to actually go and speak to different people that have some sort of... well we all have a relationship with financial markets in a way... but it's much more important to speak to people who represent different parts of society to get a perspective of how things may look from different points of view.

These examples illustrate how self-regulated professionals strategically use helpseeking. They draw on their professional and personal networks, rather than limiting their search for expertise to within their core team. This strategy for self-improvement reflects Engeström's (2014) idea of developing knowledge through negotiation within and across groups, teams and collectives.

Professionals who report poor self-regulation tended to seek help within a narrow network of people. Although they did not appear to use fewer learning approaches, those who report low SRL are more reliant on team members or managers to help them plan their learning and appear less pro-active in scoping knowledge from outside familiar boundaries. This finding is evidenced in several examples, including the case of a Manager in a business support function (83, ranked 27th for task strategies and 29th for SRL). The Manager described learning how to develop a new business process for assurance testing. At first he described how he asked others for help:

Referring to our risk manager for clarification... In executing the test we have to declare the results and there was no challenge to those results, so effectively that sort of implies that the learning was effective. 
On the surface, this case is similar to the examples described by good self-regulators. However, deeper analysis evidences that this Manager's focus is on the immediate task and he exhibits a lower degree of monitoring and adaptation of the learning strategy compared with the earlier example of a good self-regulation. Similarly, another Manager working in a business support function (76: 30th for task strategies and 30th for SRL) described how he learned how to develop a standard procedure for customers with personal finance problems: 'We sat... with our line manager and just basically brain stormed what we (were) actually required to do.' Learning is limited here to the immediate knowledge he and his colleagues need to know to complete the task, since he did not consult other people outside his core team. Learning is viewed in this instance as being regulated by the group, rather than as being a form of continual self-improvement. There was little evidence of monitoring and adjusting learning methods. In general, low self-regulators seem less likely to monitor, adapt or change their learning strategy.

In summary, professionals who perceive themselves as poor at task strategies focus their activity on learning the knowledge they need for their immediate work tasks. However, self-regulated professionals implement a range of qualitatively diverse learning approaches targeted towards current work activities while, at the same time, supporting ongoing learning and self-improvement.

\section{Self-Evaluation of Learning}

Professionals' self-evaluation draws upon a range of signals and measures. Some professionals rely on the types of self-assessment methods that are associated with performance review or discussions with their manager, to provide them with a measure of their learning and performance. Others are able to self-evaluate their learning, employing mechanisms to compare their own work with expert performance. Six out of nine professionals who reported low self-evaluation focused on evaluation methods associated with professional development processes (PDP). However, only one out of nine professionals who reported good self-evaluation mentioned formal PDP, whereas eight described self-determined forms of evaluation embedded within their work activity. One of these was a Unit Manager of a call centre (86: ranked second for self-evaluation and twelfth for SRL) who was required to gain certification in 'investment forbearance reporting procedures'. His employer organised a centralised webinar on forbearance reporting procedures to comply with employee training regulations. Training is routinely provided through online webinars with participation as a measure of learning. The training provides organisations with a mechanism to measure compliance with finance regulations, ensuring professionals are accredited to a specific level of competence. By participating in the webinar, the Unit Manager was evaluated by his organisation's professional development system as having learned about forbearance reporting and was therefore deemed as accredited. This is a common situation where Human Resource departments consider professionals to have learned through participation alone. This form of evaluation is popular with organisations because of the ease of measurement, but it offers a poor appraisal of learning. From our observations of the ways professionals self-evaluate their learning, it seems that professionals view self-evaluation and evaluation as serving different purposes, depending on their motivations and goals. In the case of the Unit Manager described 
above, although he was certified to carry out forbearance reporting he recognised he was:

No further forward in being able to do what they were asking me to do... I knew there were subject matter experts [in this topic] based in another unit. So I arranged to go and spend time with them ... so they could show me how it worked.

He understood that he could learn by applying the information he had learned through the training within his day-to-day work tasks and by working with experts:

Having spent a short time with them, I learned far more from that experience than I did from the webinar training side of things... It was only by taking individual responsibility to learn how this is done, rather than someone 'deliver' it to me, that we actually... achieved the aim.

The Unit Manager recognised the importance of the interplay between professional development planning and self-evaluation:

At the beginning of every year I effectively draft up my own PDP [Professional Development Plan] for the year, what it will look like. Effectively, I take ownership of that and report back to my line manager... The training and development is very much the ownership of the individual, not of the management.

This statement illustrates the dynamic interplay between self-assessment in performance review and self-improvement through professional learning, linking training and certification with expertise development and learner agency. This example, along with the scenario of the Investment Complaints Manager (82: ranked second for self-evaluation, ninth for SRL) described in the previous section, illustrates the importance of being able to balance structured learning opportunities with work-based learning, in agreement with previous observations by Billett et al. (2008) and Eraut (2004).

Self-evaluation does not simply focus on planning, but instead mediates and selfregulates learning. In this sense, the 'self' is viewed as active and capable of change, with self-efficacy becoming important (Bandura 1982). The mediating role of selfevaluation as a way of guiding self-improvement by comparing self-performance with expert-performance is further illustrated in the case of an Investment Complaints Manager (82: ranked second for self-evaluation, ninth for SRL). This Manager 'shadowed' an experienced colleague at a different site, acknowledging that the opportunity to learn from and compare performance with an expert was a more effective way to learn than training:

It wasn't a case of "Can you go down and get some [formal] learning?" It was a case of "This is what I want to do to make sure I can do the job to the highest level." I believe that that was the right thing for me. It has achieved the goal for me and it has made me more knowledgeable. 
Not all professionals view self-evaluation embedded within work practice as a means of guiding self-improvement. One example is a Manager (74: ranked 27th for selfevaluation and 27th for SRL) who had been assigned greater responsibility for strategic business planning. Learning was not viewed as an integral part of work performance:

My job isn't to keep learning... there should be time to learn and develop, but if all I did was professional development of myself I'd never get anything done.

When asked by the interviewer to describe how her learning was evaluated, she responded:

[Through] someone else's validation of my work, rather than my own. So far everyone internally is really pleased because we got something, but it's not quite the same as someone saying "Yeah what you've developed here shows that you've achieved your learning outcome and you've gained a whole new set of skills and you're really good at it."

Rather than viewing experts as a point of reference with which she could compare her own performance, this Manager appeared to view evaluation as a task that was carried out by a specialist. She appeared to have difficulty in self-evaluating her learning:

It's very hard to say at the end of this that I'm now a better head of strategic implementation.

Here, the Manager acknowledges difficulties with recognising whether new knowledge has been acquired or not, which is particularly problematic where tacit knowledge has become so embedded within her practice that it is difficult for her to explicate them. This difficulty has been highlighted by Eraut (2000).

Self-evaluation is challenging where individuals have trouble recognising learning and development through everyday work. There are examples where colleagues, particularly managers, can help trigger self-evaluative behaviour. For example, a risk analyst $(63,27$ th for self-evaluation, 25th for SRL) described how his manager prompted him to self-evaluate:

When you sit down with your line manager and he says "Well you're the business expert now on [topic]" and you're kind of "I don't really think so" and he says "Well think about where you've come from and what you've learnt, the amount of people that are coming to you now with questions on [topic], that to me shows that you've learned a hell of a lot, where you're seen as the first point of contact to provide advice to the business."

When asked how often he learned, his response highlighted how professional learning may not be recognised immediately:

All the time, I learn every day... I don't always think I learn every day, but when I come and do my monthly ones-to-ones or something with my line manager, that's where it comes out. 
This difficulty in recognising learning was also observed by Eraut (2000) in his observations of informal learning in the workplace.

Overall, these professionals who report low self-regulation find it difficult to recognise when they learn. They may focus on self-assessment through professional development planning. By contrast, professionals who report good self-regulation distinguish between extrinsic self-assessment and intrinsic self-improvement, comparing their personal achievements with expert performance. Self-evaluation helps them organise their learning in work-based contexts.

\section{Discussion and Conclusions}

This study analysed narrative descriptions of learning in the financial services industry, examining in detail three sub-processes of self-regulated learning previously identified as predictors of enhanced workplace learning activity. The professionals in this study who reported good self-regulation tended to have a progressive, long-term, developmental view of their learning, looking beyond the immediate work task and assessment of the immediate applications. Through this long-standing perspective, these selfregulated professionals prepared themselves for future, unforeseen work scenarios, which is important for ongoing improvement and innovation and the adoption of new practices. The professionals who reported low self-regulation were more jobfocused, tending to limit their personal and professional development towards immediate, known tasks. This qualitative difference in how professionals self-regulate their learning through these three significant SRL sub-processes task interest and value, task strategies, and self-evaluation is summarised in Table 2:

Professionals who perceive themselves as having low interest and value in learning tasks tend to align their learning with immediate work performance and 'getting the job done'. They view success in terms of effective completion of these tasks and like to demonstrate their ability as a professional, both to themselves and to the organisation. This form of self-

Table 2 Summary of differences in SRL behaviour between groups of professionals who scored low and high for the three SRL sub-processes

\begin{tabular}{|c|c|c|}
\hline Sub-process & Professionals reporting good SRL & Professionals reporting low SRL \\
\hline Task interest and value & $\begin{array}{l}8 / 10 \text { focused on long-term benefit } \\
\text { of the learning they described. }\end{array}$ & $\begin{array}{l}\text { 2/7 focused on long-term benefits, while } \\
\text { all described benefits in relation to } \\
\text { solving immediate challenges. }\end{array}$ \\
\hline Task strategies & $\begin{array}{l}\text { 7/9 broke down their learning into } \\
\text { bits } \\
8 / 9 \text { purposefully selected a method } \\
\text { to suit a specific learning task. }\end{array}$ & $\begin{array}{l}\text { 3/9 broke down their learning into smaller } \\
\text { chunks. } \\
\text { 2/9 purposefully selected a method to suit } \\
\text { a specific learning task. The others } \\
\text { described their learning as mediated by } \\
\text { other people (working with their manager } \\
\text { or other members of their team). }\end{array}$ \\
\hline Self-evaluation & $\begin{array}{l}\text { 1/9 used training methods. } \\
\text { 8/9 adopted self-evaluation strategies. }\end{array}$ & $\begin{array}{l}6 / 9 \text { used training methods. } \\
2 / 9 \text { adopted self-evaluation } \\
\text { (the } 9 \text { th mentioned self-evaluation, but } \\
\text { only when prompted). }\end{array}$ \\
\hline
\end{tabular}


verification reflects the individual's wish to be known and understood by others as a 'professional', in line with their own beliefs and feelings about themselves. Professionals who are self-regulated are more likely to be concerned with self-enhancement - behavior that helps them feel good about themselves and maintains self-esteem - since they find interest and value in a broad range of learning tasks. They tend to link current learning to their past experience and consider how this learning might improve future performance, beyond the horizon of the stimulus task. Self-regulators perceive learning as a form of longterm, personalised self-improvement. There is limited evidence that positive emotions (for example, pride in work or satisfaction associated with learning) or negative emotions (such as dissatisfaction or disappointment) influence self-regulation.

Professionals who perceive themselves as poor at task strategies carry out activities to learn the knowledge they need for their immediate work task. They tend to limit their learning to what they - and their colleagues - need to know to complete an immediate task. In contrast, those who are self-regulated implement a range of qualitatively diverse learning approaches. These learning approaches are not only targeted towards work activities, but also support ongoing learning and self-improvement. Professionals who are not self-regulating may have difficulty recognising when they learn. They tend to align their self-evaluation with self-assessment through professional development planning and other forms of extrinsic benchmarking. However, those who perceive themselves as good at self-evaluation understand learning as an integral part of work performance. They tend to distinguish between extrinsic self-assessment and intrinsic self-improvement, comparing their personal achievements with expert performance. The ability to self-evaluate helps them recognise the limitations of training and to complement (or supplant) education with on-the-job learning. Poor self-regulators sometimes have difficulty recognising when they learn, whereas those who score high view self-reflection on learning as an integral part of achieving work tasks. While the work task and work environment will inevitably influence the degree of self-reflection, we did not find an alignment between specific types of job role, environment or task and degree of self-regulation. However, there do seem to be complex inter-relationships across the SRL sub-processes.

Overall, we observe self-regulation as a variable capability. Some professionals in this study appeared to understand how to regulate their learning, yet chose not to selfregulate. This study cannot provide definitive answers as to why some professionals choose to self-regulate their learning while others do not. However, the research identifies a key characteristic of self-regulation as viewing learning as long-term, personalised self-improvement. By presenting evidence of how professionals selfregulate their learning, this study provides a foundation for future policy and planning in organisations. Organisations could encourage professionals to understand the importance of professional learning as well as education and training for the individual and the organisation. The Chartered Institute for Securities \& Investment is using the outcomes of this study to advise finance organisations in how to plan environments that encourage self-regulated learning.

\section{Limitations and Further Work}

As with any study, there are limitations to this research. The sample represented a range of roles and organisational contexts across the sector. While this sampling approach 
renders the findings relevant to the sector as a whole, heterogeneity in the sample cohort makes it difficult to generalise the results. Further work, adopting similar methods with homogeneous samples (single organisations, specific roles), would allow analysis of how SRL behaviours are enacted in different workplace contexts. A second limitation is the heterogeneous nature of the learning situations studied, with examples reported ranging from precise (implementing new processes to comply with new legislation) to broad (developing greater cultural understanding of a new market). Not every learning description yields information about every SRL sub-process, so the opportunity for comparison across the data is eroded. An alternative, to more closely specify the learning situation, would compromise the validity of the data collected, as any selected learning situation may not be authentic for all study participants. A final limitation of the study is the lack of a robust measure of learning. We are reliant on individual self-report to ascertain whether the learning described was successful. In-depth studies which analysed specific learning events in greater detail - for example, by collecting the views of peers and managers, or by following learners over a longer period of time - would be more coherent. Longitudinal studies, in particular, would be attractive, as these would allow exploration of the impact of learning which may not arise immediately and would allow exploration across cycles of selfregulation.

Acknowledgments This research would not have been possible without expert insight, significant support and input from industry lead George Littlejohn, Senior Advisor, Chartered Institute for Securities and Investments, London, UK. We are grateful to the Chartered Institute of Securities and the CISI members who agreed to be interviewed for the study. We would also like to thank the reviewers and editor for their comments during the review process.

Open Access This article is distributed under the terms of the Creative Commons Attribution 4.0 International License (http://creativecommons.org/licenses/by/4.0/), which permits unrestricted use, distribution, and reproduction in any medium, provided you give appropriate credit to the original author(s) and the source, provide a link to the Creative Commons license, and indicate if changes were made.

\section{References}

Argyris, C., \& Schön, D. A. (1992). On organizational learning. Cambridge: Blackwell.

Bandura, A. (1982). Self-efficacy mechanism in human agency. American Psychologist, 37(2), 122.

Bandura, A. (1986). Social foundations of thought and action: A social cognitive theory. Englewood Cliffs: Prentice Hall.

Billett, S. (2004). Co-participation at work: learning through work and throughout working lives. Studies in the Education of Adults, 36(2), 190-205.

Billett, S., Harteis, C., \& Eteläpelto, C. (Eds.). (2008). Emerging perspectives of workplace learning. Rotterdam: Sense.

Collin, K. (2004). The role of experience in work and learning among design engineers. International Journal of Training and Development, 8(2), 111-127.

Collin, K. (2008). Development engineers' work and learning as shared practice. International Journal of Lifelong Education, 27(4), 379-397.

Edwards, A. (2010). Being an expert professional practitioner: The relational turn in expertise (Vol. 3). Springer science \& business media. Dordrecht: Springer.

Engeström, Y. (1999). Innovative learning in work teams: analyzing cycles of knowledge creation in practice. In Y. Engeström, R. Miettinen, \& R.-L. Punamäki (Eds.), Perspectives on activity theory (pp. 377-404). Cambridge: Cambridge University Press. 
Engeström, R. (2014). New forms of transformative agency. In A. Littlejohn \& A. Margaryan (Eds.), Technologyenhanced professional learning: Processes, practices and tools (pp. 59-70). London: Routledge.

Enos, M. D., Kehrhahn, M. T., \& Bell, A. (2003). Informal learning and the transfer of learning: How managers develop proficiency. Human Resource Development Quarterly, 14(4), 369-387.

Eraut, M. (1995). Schön Shock: a case for refraining reflection-in-action? Teachers and Teaching: Theory and Practice, 1(1), 9-22.

Eraut, M. (2000). Non-formal learning and tacit knowledge in professional work. British Journal of Educational Psychology, 70, 113-136.

Eraut, M. (2004). Informal learning in the workplace. Studies in Continuing Education, 26(2), 247-273.

Eraut, M. (2007). Learning from other people in the workplace. Oxford Review of Education, 33(4), 403-422.

Ericsson, K. A., \& Lehmann, A. C. (1996). Expert and exceptional performance: evidence of maximal adaptation to task constraints. Annual Review of Psychology, 47, 273-305.

Fontana, R. P., Milligan, C., Littlejohn, A., \& Margaryan, A. (2015). Measuring self-regulated learning in the workplace. International Journal of Training and Development, 19(1), 32-52.

Fuller, A., \& Unwin, L. (2004). Expansive learning environments. Integrating organizational and personal development. In H. Rainbird, A. Fuller, \& A. Munro (Eds.), Workplace learning in context (pp. 126-144). London: Routledge.

Harteis, C., \& Billett, S. (2008). The workplace as learning environment. International Journal of Educational Research, 47, 209-212.

Littlejohn, A., \& Hood, N. (under review). Knowledge typologies for professional learning: educators' (re)generation of knowledge when learning open educational practice.

Littlejohn, A., \& Margaryan, A. (2013). Technology-enhanced professional learning: Mapping out a new domain. In A. Littlejohn \& A. Margaryan (Eds.), Technology-enhanced professional learning: Processes, practices and tools (pp. 1-13). London: Routledge.

Ludvigsen, S. R., Lund, A., Rasmussen, I., \& Säljö, R. (Eds.). (2010). Learning across sites: New tools, infrastructures and practices. London: Routledge.

Margaryan, A., Milligan, C., Littlejohn, A., Hendrix, D., \& Graeb-Koenneker, S. (2009). Selfregulated learning and knowledge sharing in the workplace. In Proceedings of the 2009 International Conference on Organisational Learning, Knowledge and Capabilities (OLKC), Amsterdam, Netherlands.

Margaryan, A., Littlejohn, A., \& Milligan, C. (2013). Self-regulated learning in the workplace: learning goal attainment strategies and factors. International Journal of Training and Development, 17(4), 254-259.

Marsick, V. J., \& Watkins, K. E. (1990). Informal and incidental learning in the workplace. New York: Routledge.

Milligan, C., Fontana, R. P., Littlejohn, A., \& Margaryan, A. (2015). Self-regulated learning behaviour in the finance industry. Journal of Workplace Learning, 27(5), 387-402.

Pintrich, P. R. (2000). The role of goal orientation in self-regulated learning. In M. Boekaerts, M. Zeidner, \& P. R. Pintrich (Eds.), Handbook of self-regulation (pp. 451-502). San Diego: Academic.

Rausch, A. (2013). Task characteristics and learning potentials - empirical results of three diary studies on workplace learning. Vocations and Learning, 6, 55-79.

Schulz, M., \& Stamov Roßnagel, C. (2010). Informal workplace learning: an exploration of age differences in learning competence. Learning and Instruction, 20(5), 383-399.

Sitzmann, T., \& Ely, K. (2011). A meta-analysis of self-regulated learning in work-related training and educational attainment: what we know and where we need to go. Psychological Bulletin, 137(3), 421-442.

Stacey, R. D. (2001). Complex responsive processes in organizations: Learning and knowledge creation. London: Routledge.

Stenström, M.-L., \& Tynjälä, P. (Eds.). (2009). Towards integration of work and learning: Strategies for connectivity and transformation. Amsterdam: Springer.

Tynjälä, P. (2008). Perspectives into learning at the workplace. Educational Research Review, 3(2), 130-154.

Unwin, L., Felstead, A., \& Fuller, A. (2004). Learning at Work: Towards more Expansive Opportunities. Paper prepared for the NIACE Commission of Inquiry into 'The Future for Lifelong Learning'. http:// www.niace.org.uk/lifelonglearninginquiry/ docs/Workplace-Lorna-Unwin.pdf

van den Boom, G., Paas, F., van Merriënboer, J., \& van Gog, T. (2004). Reflection prompts and tutor feedback in a web based learning environment: Effects on students self-regulated learning competence. Computers in Human Behavior, 20(4), 551-567.

van Eekelen, I. M., Boshuizen, H. P. A., \& Vermunt, J. D. (2005). Self-regulation in higher education teacher learning. Higher Education, 50(3), 447-471.

Winne, P. H. (1995). Inherent details in self-regulated learning. Educational Psychologist, 30(4), 173-187. 
Zimmerman, B. J. (1989). A social cognitive view of self-regulated academic learning. Journal of Educational Psychology, 81(3), 329-339.

Zimmerman, B. J. (2000). Attaining self-regulation: A social cognitive perspective. In M. Boekaerts, M. Zeidner, \& P. R. Pintrich (Eds.), Handbook of self-regulation (pp. 13-39). San Diego: Academic.

Zimmerman, B. J. (2002). Becoming a self-regulated learner: an overview. Theory Into Practice, $41(2), 64-70$.

Zimmerman, B. J., \& Martinez Pons, M. (1986). Development of a structured interview for assessing student use of self-regulated learning strategies. American Educational Research Journal, 23(4), 614-628.

\begin{abstract}
Allison Littlejohn is Professor of Learning Technology and Academic Director of Learning and Teaching at the Open University, UK. She leads a research portfolio in technology-enhanced professional learning and has received research funding from an array of organisations including research councils, funding councils, professional bodies and industry partners. She was Shell Senior Researcher 2008-10.
\end{abstract}

Colin Milligan is a Research Fellow in the Caledonian Academy at Glasgow Caledonian University, UK. He has a degree from the University of Edinburgh and $\mathrm{PhD}$ from the University of Glasgow, UK. His primary research interest is the professional learning undertaken by knowledge workers and the personal learning networks they construct to support this learning.

Rosa Pia Fontana was a Researcher in the Caledonian Academy at Glasgow Caledonian University, UK. She has a degree and $\mathrm{PhD}$ in Organisational Psychology from the University if Bari, Italy.

Anoush Margaryan is a Full Professor and Acting Director of the Caledonian Academy, a research centre for technology-enhanced professional learning at Glasgow Caledonian University. She studies how people learn in the workplace in knowledge-intensive domains, and how they currently use or could potentially use digital technologies to support their learning. She has led over 15 collaborative research projects funded by research councils, supranational organisations, industry and professional bodies and has over 100 publications including two books. http://www.gcu.ac.uk/academy/people/anoush-margaryan/. 